
формированию информационной компетенции библиотечных специалистов, работающих с информационно-правовыми системами

Реферат. В статье рассматриваются проблемы обеспечения свободного доступа пользователей к информационным ресурсам в библиотеках на примере работы библиотекарей с информационно-правовыми системами (ИПС). Анализируются вопросы развития профессиональных компетенций в библиотечной сфере. Представлен тренинг, используемый в Российской государственной библиотеке, как метод формирования информационной компетенции. Показана его эффективность для пользователей ИПС ( ККонсультантПлюс», «Гарант», «Техэксперт», «Законодательство СНГ»), а также систем официальных интернет-порталов (ИПС «Законодательство России», НЦПИ «Эталон» и др.). Раскрыты составные части тренинга: технологическая карта для конструирования занятий, примеры тренировочных заданий. Осуществлен опрос пользователей с целью получения их оценки о форме проведения и содержании лекций-тренингов, выявления уровней знаний, умений и навыков работы с ИПС. Даны методические рекомендации для библиотекарей на основе компетентностного подхода по использованию ИПС. Результаты исследования могут быть востребованы в рамках методической работы библиотек по формированию профессиональных компетенций библиотечных кадров, работающих как с ИПС, так и с другими электронными ресурсами.

Ключевые слова: библиотеки, библиотечное обслуживание, пользователи, информационные ресурсы, информационно-правовые системы, компетентностный подход, информационная компетенция, тренинг, методическая работа.

Для цитирования: Ракитская Л.М. Методическая работа по формированию информационной компетенции библиотечных специалистов, работающих с информационно-правовыми системами // Библиотековедение. 2016. Т. 65, № 6. С. $701-708$.

\section{Информационно-правовые системы как современный ресурс предоставления правовой информации в библиотеках}

Динамика изменений российского законодательства и его колоссальный объем требуют от специалистов различного профиля использования современных инструментов в работе с правовой информацией. В настоящее время этими инструментами являются информационно-правовые системы (ИПС) - особый класс электронных баз данных (БД), содержащих систематизированную и оперативно обновляемую информацию по за-

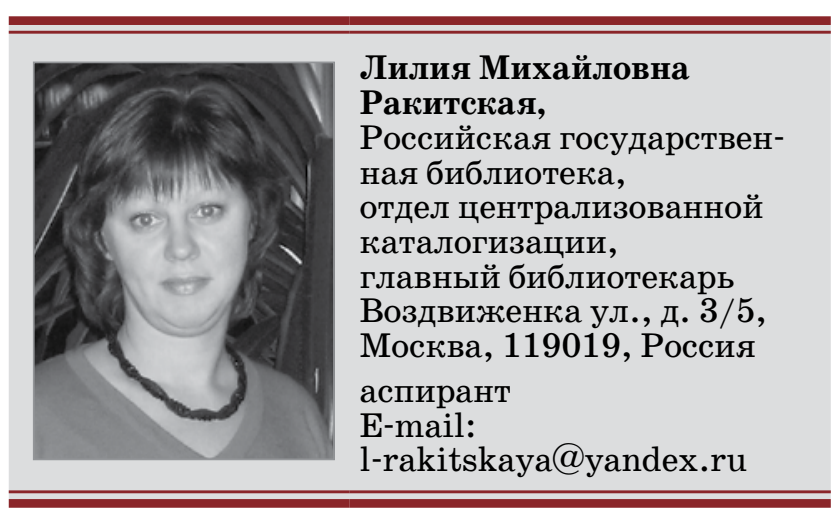


конодательству, а также программные средства поиска, анализа и обработки этой информации [1, c. 52]. Основная задача ИПС - донести максимум достоверной правовой информации до широкого круга пользователей.

До появления ИПС специалистам приходилось затрачивать много времени на поиск документов, тематических подборок правовых актов, других взаимосвязанных по какой-либо правовой проблеме источников. Сегодня эта часть работы упростилась, существенно уменьшилось время на поиск необходимой информации. С помощью ИПС можно быстрее и эффективнее решать спорные вопросы в различных сферах деятельности, они обладают рядом преимуществ, делающих их практически незаменимыми в работе с нормативно-правовой документацией. Это возможность работы с огромными массивами текстовой информации, использование специальных программных средств для осуществления поиска документов в режиме реального времени по всей БД, их тематическая классификация, поиск по ключевым словам, установление и отражение взаимосвязей документов и т. д. Большинство БД позволяют не только быстро найти необходимую правовую информацию, но и сразу же автоматически получить представление обо всей системе нормативных актов, касающихся данного вопроса.

Условно ИПС можно разделить на две группы:

- официальные - содержащие тексты указов, постановлений и решений различных государственных органов и разработанные ими, и

- справочные - которые, кроме нормативных документов, содержат комментарии к законодательству, консультации специалистов по праву, бухгалтерскому и налоговому учету, судебные решения, типовые формы деловых документов и др., поддерживаются и распространяются фирмами и компаниями на коммерческой основе.

К первой группе относятся: ИПС «Эталонный банк правовых актов» (Научно-технический центр «Система» Федеральной службы охраны Российской Федерации (ФСО РФ)), ИПС «Законодательство России» - сетевой ресурс «Официального интернет-портала правовой информации» (входит в государственную систему правовой информации, функционирование которой обеспечивает Спецсвязь ФСО РФ), БД «ЭталонПлюс» (Научный центр правовой информации Министерства юстиции РФ).

Многие федеральные институты и центры информации организуют пользователям доступ к БД по отдельным видам документов: Российский научно-технический центр информации по стандартизации, метрологии и оценке соответствия (ФГУП «Стандартинформ») - по стандартам и техническим условиям; Российский научно-исследовательский институт информационных технологий и систем автоматизированного проектирования Министерства образования и науки
РФ - по промышленным каталогам; Федеральный институт промышленной собственности и Информационно-издательский центр «Патент» - по объектам промышленной собственности (изобретениям, полезным моделям, промышленным образцам, товарным знакам, знакам обслуживания, наименованиям мест происхождения товаров).

Вторую группу ИПС образуют: справочноправовая система «КонсультантПлюс» (АО «КонсультантПлюс»), информационно-правовое обеспечение «Гарант» (Научно-производственное предприятие «Гарант-Сервис»), ИПС «Кодекс», «Техэксперт» (Центр компьютерных разработок, Санкт-Петербург), ИПС «Законодательство СНГ» (Компания «СоюзПравоИнформ»). Они помогают пользователю защитить свои права как потребителя услуг, уточнить права как гражданина, оформить различного рода сделки и пр., не только обращаясь к нормам закона, но и к анализу правовой информации.

ИПС активно используются в процессе библиотечного обслуживания, поскольку предоставление правовой информации населению - одна из важных современных функций российских библиотек. ИПС достаточно объемны, часто содержат уникальные документы, но работа с ними требует особых компетенций от библиотекарей. Это вызвано несколькими причинами: во-первых, фирмы-разработчики ИПС постоянно совершенствуют технологические процессы и возможности программных оболочек, расширяют спектр хранящихся в БД документов; во-вторых, к ИПС обращаются пользователи с различным уровнем компьютерной и правовой грамотности, многие из которых вынуждены прибегать к помощи библиотекаря, выступающего в этом случае в роли консультанта.

\section{Информационная компетентность библиотечного специалиста}

Потребность пользователей библиотек в консультировании по применению ИПС выдвигает более высокие требования к библиотекарям как профессионалам. Библиотечным специалистам необходимы знания ИПС с точки зрения их интерфейса и поисковых возможностей, умения анализировать, отбирать, обрабатывать и передавать необходимую информацию, навыки владения информационными ресурсами, т. е. необходим высокий уровень профессиональных компетенций.

Термин «информационная компетенция 》 определяется качеством действий работника, обеспечивающих: эффективное восприятие и оценку информации, отбор и синтез информации в соответствии с системой приоритетов; использование информационно-коммуникационных технологий (ИКТ) в профессиональной деятельности; работу с различными информационными источниками и ресурсами, позволяющими проектировать ре- 
шение управленческих, педагогических проблем и практических задач, ведение документации на электронных носителях [2, с. 8-9].

В библиотечной сфере под информационной компетентностью - важнейшей составляющей профессиональной компетентности библиотекаря - понимается содержание и степень удовлетворения информационных потребностей личности; знание способов и закономерностей поиска, обработки, передачи, обмена, хранения информации в пространстве и во времени; умение их использовать в различных сферах своей деятельности [3, с. 47]. Особенности информационной компетентности библиотекаря заключаются в том, что знания, умения и навыки использования ИКТ входят и в профессиональную модель, и в модель ключевых компетенций индивида начала XXI века. В общем виде информационная компетентность представляется как двухэлементная система, включающая ключевые и профессиональные компетенции. Таким образом, информационная компетентность - это развитие библиотекаря и как профессионала, и как личности.

Понятие «информационная компетентность» некоторые исследователи, в частности Н.И. Гендина, рассматривают во взаимосвязи с такими понятиями, как «компьютерная грамотность», «информационная культура», которые являются важнейшими факторами успешной профессиональной деятельности [4; 5]. М.С. Мамонтова выстраивает целый комплекс знаний и умений библиотекаря, в числе которых: знание теории информации и информационного поиска, руководящих и нормативных документов, регламентирующих функционирование информации в обществе; знание рациональных методов поиска, обработки и хранения информации в современных информационных массивах; владение навыками работы с информацией, представленной в электронном и бумажном виде, а также использование телекоммуникационных, массмедийных и информационных технологий в конкретном библиотечном процессе; умение организовать самостоятельную работу читателей посредством интернет-технологий и др. [6].

Таким образом, информационная компетентность как ключевая компетентность библиотечного специалиста включает в себя специальные знания, умения и навыки, позволяющие принимать эффективные решения в профессиональной и личностной деятельности.

Результаты проведенного терминологического анализа показывают, что информационная компетентность трактуется учеными достаточно разнообразно в зависимости от выбранного направления и необходимого уровня охвата понятия. В дальнейшем под информационной компетентностью библиотекаря мы будем понимать совокупность знаний, умений и ценностного отношения к эффективному осуществлению библио- течно-информационной деятельности, включая использование ИКТ для оптимального решения профессиональных задач.

\section{Методическая работа как инструмент формирования профессиональных компетенций библиотекаря}

Формирование профессиональных компетенций библиотекарей возможно путем повышения их квалификации, поддержания и развития уровня профессиональных компетенций, включая информационную в рамках методической работы библиотек.

Итак, для библиотек особое значение приобретает организация методической работы по обслуживанию пользователей информационными ресурсами и повышение квалификации библиотекарей. При этом формирование информационной компетенции в библиотеке должно быть специально организованным, целенаправленным процессом, предполагающим проведение обучения пользователей специальным информационным знаниям и умениям (в нашем случае по работе со справочно-правовыми системами, официальными интернет-порталами правовой информации).

Ведущим звеном в формировании информационной компетенции должны стать методические центры библиотек, а главная задача методистов - создать условия для ее формирования. Осуществление методической работы на основе компетентностного подхода невозможно без обеспечения качества повышения квалификации библиотечных специалистов, которое предполагает мобильность содержания, информатизацию процесса обучения, использование активных форм и методов, атмосферу сотрудничества библиотекарей и методистов. Главным условием изменения содержания и организации методической работы в рамках компетентностного подхода является реализация форм и методов обучения, которые создавали бы ситуации включения библиотекарей в разные виды деятельности (общение, решение проблем, дискуссии, диспуты, выполнение проектов и др.). Поскольку компетентностный подход предполагает существенное усиление практической направленности обучения, самостоятельности субъекта в процессе профессиональной деятельности, то информационная компетенция формируется группой активных методов, среди которых одно из основных мест занимает тренинг.

Цель тренинга — формирование информационной компетенции библиотечного специалиста как совокупности знаний, умений и навыков в профессиональной области, ценностного отношения к эффективному осуществлению библиотечно-информационной деятельности и использованию современных ИКТ для оптимального решения задач в этой сфере. 
Методика проведения занятия способом группового тренинга требует от ведущего большой подготовительной работы: над планом (сценарием) тренинга; с пользователями - для того, чтобы настроить их на активное участие в решении проблемы, выносимой на тренинг; самоподготовки методиста-ведущего; распределения ролей между участниками.

Рассмотрим применение лекции-тренинга в Российской государственной библиотеке для развития информационной компетенции на примере использования ИПС.

Лекции-тренинги разбиваются на отдельные занятия (темы) продолжительностью 60 минут. Все темы структурированы одинаково, в начале каждой имеется основной блок, в котором на основе подробно разобранных примеров представлены возможности ИПС. Затем идет блок примеров самостоятельных тренировочных заданий для пользователей по поиску правовой информации (на каждом занятии рекомендуется выделить для этого некоторое время). Целесообразно заранее подготавливать комплекты тренировочных заданий для пользователей с разными уровнями работы с системой (высокий, средний, низкий). Для удобства обучения все пользователи, занятые в лекциях-тренингах, обеспечиваются информационными материалами, из которых можно получить сведения по работе с системой, тренировочные задания, поясняющие таблицы и схемы. Во время проведения тренинга ведущий может оказать помощь в возникшей проблеме, объяснив один из способов ее решения, тем самым наводя пользователя на поиск других алгоритмов. В конце тренинга проводится разбор практических ситуаций со всеми участниками группы. Рекомендуется также проводить опрос пользователей с целью получения их оценки о форме проведения и содержании лекций-тренингов, выявления уровня знаний, умений, навыков по работе с ИПС, наиболее предпочтительные способы поиска правовой информации в ИПС. Результаты опроса (анкетирования), примеры тренировочных заданий для пользователей ИПС рассматривались нами ранее [7].

Главная особенность лекции-тренинга заключается в том, что пользователи являются активными участниками процесса, которые не только слушают ведущего, но и работают за компьютером. Все занятия ориентированы на развитие навыков поиска информации и работы с текстами документов. Пользователи овладевают такими приемами, как поиск актов, реквизиты которых неизвестны, составление подборки документов по интересующему вопросу, определение взаимосвязи между различными актами и пр.

Выбор общей структуры занятия позволяет переходить к конструированию его конкретного содержания. Для этого применяется технологическая карта (ТК) (см. таблицу). Ее цель - пре- доставить методисту инструментарий для конструирования системы занятий по определенной теме с целью формирования профессиональных компетенций. ТК содержит формирующие технологии с наборами целей обучения, критериев оценки их достижения, форм, методов, способов, приемов, других технологических и информационных средств обучения. ТК сохраняет базовые объекты изучаемого материала, технологические этапы обучения. С помощью такой карты можно обеспечить достижение одних и тех же целей различными наборами форм и методов занятий, которые применяются в качестве вариативных средств, дополняющих базовую структуру.

ТК состоит из блоков: вводная часть, основная часть, тренинг, контроль, рефлексия. У каждого блока имеются свои задачи и формирующие технологии. Работа выстраивается следующим образом. Из каждого блока ТК выбираются виды деятельности, формы, методы, приемы, средства обучения, с помощью которых предполагается достичь поставленных целей. Ориентиром для методиста при планировании системы занятий является формирование профессиональных компетенций. Этот процесс соотносится с личностным потенциалом пользователей, содержанием материала и организационными формами, усвоением пользователями информационного блока лекциитренинга.

С точки зрения вводной, основной и практической частей ТК информационная компетенция рассматривается как система знаний и умений, влияющих на профессиональную деятельность библиотекаря, которые могут быть измерены и развиты через обучение. На этапе контроля деятельности происходит оценка уровня достижения поставленной цели - формирования информационной компетенции. Уровневый подход заключается в определении информационной компетенции как этапа развития профессионала от новичка до эксперта. В рамках данного подхода информационная компетенция рассматривается как совокупность определенных уровней, которым библиотекари могут соответствовать в большей или меньшей степени. Заметим, что при таком определении наблюдается связь компетенции с профессионализмом и уровнем квалификации специалиста. Более того, уровневый подход определяет степень информационной компетенции, которой этот специалист должен обладать, чтобы на высоком уровне справляться с поставленными профессиональными задачами.

Для каждого уровня свойственны определенные критерии, отражающие трехуровневое проявление информационной компетенции (высокий, средний, низкий).

Высокий уровень форлирования инфорлаиионной колпетениии. Библиотекарь умеет решать вопросы получения правовой информации, хорошо ориентируется в поиске документов по 
Технологическая карта тренинга

Технологический блок

\section{Основная задача}

\section{Вводная часть}

Знакомство с основными элементами Актуализировать личный опыт и знания поль- Вводная лекция интерфейса

Преимущества и специфика ИПС

Назначение и основные характеристики поисковых возможностей системы зователей для введения в тему. Помочь им в самоопределении и личном целеполагании по отношению к теме. Разработать конспект по теме. Изучить новые поисковые возможности БД, связанные с постоянным изменением их программной оболочки (интерфейса)

Посещать занятия, организуемые фирмамиразработчиками ИПС

\section{Основная часть (информативная)}

Быстрый поиск документа

Достичь главных целей по теме, выполнить основное содержание конспекта, освоить соКарточка поиска (текст документа, держание темы дополнительная информация к документу, справка, редакции, поиск фрагмента по тексту документа, связи документа)

Поиск с использованием Правового навигатора

Авторские материалы (пресса, книги)

Справочная информация

\section{Тренинг (практическая часть)}

Разбор практических ситуаций с по- Закрепить результаты основной части блока мощью примеров тренировочных заданий для пользователей

Выполнить требования по деятельностной подготовке - освоить необходимые способы и методы

\section{Контроль}

Подведение итогов занятия (оценка Проверить и оценить уровень сформированусвоенных навыков, вопросы пользо- ной компетенции вателей)

Опрос пользователей

Обнаружить изменения в личностных качествах пользователей, их знаниях, умениях, навыках

Раздача информационных материалов

\section{Рефлексия (анализ деятельности)}

Анализ анкет респондентов

Вспомнить и осознать основные этапы за- Анкетирование, групнятия, индивидуальные и коллективные повые и индивидурезультаты деятельности, возникшие проблемы и способы их решения альные самооценки и характеристики пользователей, итоговая

Соотнести поставленные цели с результатами рефлексивная лекция обучения

интересующему вопросу. Находит и получает соответствующие разъяснения с помощью раздела «Комментарии законодательства» и консультационных материалов. Достаточно хорошо развиты навыки самоанализа: определение порядка своих действий по ситуации, выявление спорных моментов. Использует эффективные поисковые возможности ИПС ( «Правовой навигатор», «Путеводители», гиперссылки), а также в удобном виде умеет сохранять результаты работы с найденными документами, создавать собственные подборки документов, относящиеся к разным типам правовой информации (нормативные акты, судебные решения, различные консультационные материалы и т. д.).

Средний уровень форлирования инфорлационной колпетенции. Потенциал информационной компетенции не отличается высокой устойчиво- 
стью. Знания поисковых возможностей правовой БД систематизированы, однако библиотекарь не столь внимателен при поиске информации, менее гибок в нахождении соответствующих запросу консультационных материалов, форм документов, комментариев к нормативным документам, судебной практике и др. Использует для решения практической ситуации «Быстрый поиск», «Карточку поиска», реже - «Правовой навигатор». Ориентируется в простых видах поиска («Обзоры правовой информации», «Справочная информация», «Словарь финансовых и юридических терминов»). Применяет кнопку «История поисков» панели быстрого доступа, где автоматически сохраняются последние запросы с помощью «Быстрого поиска», «Карточки поиска», «Правового навигатора» при условии, что по этим запросам был произведен поиск и построен список документов. Не использует поиск «Путеводители», реже - умные ссылки, дополнительную информацию, связанную с применением документа, а также правую панель с кнопкой «Редакции». Недостаточно хорошо развиты навыки использования возможности справочной правовой системы по сохранению результатов работы: печать документов, сохранение в файл, отправка по электронной почте, создание собственного рабочего пространства (блок «Избранное»: закладки, папки, функция «Документы на контроле»). Иногда прибегает к возможностям контекстно-зависимой системы помощи, которую можно вызвать из любого места БД, нажав клавишу F1. Система помощи содержит большое количество практических примеров, помогающих понять, как следует действовать в той или иной проблемной ситуации.

Низкий уровень форлирования инфорлационной колпетениии. Стремление библиотекаря к знанию ИКТ ограничено. Неуверенно использует все поисковые инструменты справочной правовой системы ( «Быстрый поиск», «Карточка поиска», «Правовой навигатор», «Путеводители», «Обзоры правовой информации», «Справочная информация», «Словарь финансовых и юридических терминов», «История поисков»). Отсутствуют умения и навыки самостоятельной работы с информацией (анализ и отбор необходимой информации, ее преобразование, сохранение и передача). Проявление инициативы в решении проблемных ситуаций занижено.

Определяя уровни формирования информационной компетенции, мы осознаем, что в определенной мере они относительны, поскольку существуют и другие показатели. Например, в методологической литературе по компетенциям выделяют три и более уровней $[6 ; 8]$, в число которых входят: низкий (минимальный), средний (продвинутый), высокий (творческий) и т. д.

Таким образом, уровневый подход связывает информационную компетенцию с выполнением профессиональной деятельности на высоком уровне, в которую включены такие аспекты, как решение проблемы с помощью практических задач, аналитическое мышление и личностный потенциал. Связь с качественными критериями действия также означает, что по информационной компетенции можно определить, выполняется ли действие хорошо или плохо, что может быть измерено по определенным характеристикам.

Проведенная работа позволяет сделать некоторые выводы.

ИПС - один из важных ресурсов для оказания библиотечных услуг. Они различаются по своему функционалу, специфике работы, поисковым возможностям и другим параметрам, что требует от библиотекарей не просто наращивания предметных знаний, а развития информационной компетенции. Информационная компетентность в самом общем смысле ориентирована на формирование самостоятельной, ответственной, социально-активной личности, способной к решению возникающих производственных и социальных проблем, выполнению профессиональных функций на основе применения ИКТ. В библиотечном деле востребованными становятся работники, обладающие знаниями, умениями, навыками грамотного и осознанного использования ИКТ в своей деятельности, готовые к постоянному совершенствованию профессионального уровня.

Имеются различные подходы к пониманию информационной компетенции библиотечного специалиста. В качестве цели при реализации компетентностного подхода в повышении квалификации выступает формирование компетентного специалиста: создание условий для овладения компетенциями, способности и готовности специалиста применить их в практической деятельности. Использование в методической работе тренинга как метода обучения, включающего деловые и ролевые игры, групповые дискуссии, разбор практических ситуаций, способствует продуктивному структурированию информации, развитию знаний, умений, навыков работы с ИПС.

Проведенное исследование подтвердило предположение о целесообразности применения лекции-тренинга как способа формирования профессиональных компетенций у библиотекарей. Наибольший эффект приносит систематическое проведение тренингов с одной группой пользователей. Внедрение методических материалов и рекомендаций позволит библиотечным специалистам повысить квалификацию, сформировать компетенции, необходимые для профессиональной деятельности.

\section{Список источников}

1. Шельменков В.Н. Правовое обеспечение функционирования информационно-справочных систем в Российской Федерации // Мониторинг правоприменения. 2012. № 3. С. 52-56.

2. Прием на работу. Заключение трудового договора : учеб.-практ. пособие / И.Я. Белицкая, Ю.С. Коряки- 
на, Д.Л. Кузнецов и др. ; отв. ред. Ю.П. Орловский. Москва : Контракт ; Волтерс Клувер, 2011. 288 с.

3. Паршукова Г.Б. Информационная компетентность личности. Диагностика и формирование : монография / Новосиб. гос. техн. ун-т, Гос. публич. науч.-техн. б-ка Сиб. отд-ния Рос. акад. наук. Новосибирск : Изд-во Новосиб. гос. техн. ун-та, $2006.253 \mathrm{c}$.

4. Гендина Н.И. Информационная грамотность или информационная культура: альтернатива или единство (результаты российских исследований) // Школьная библиотека. 2005. № 3. С. 18-24.

5. Гендина Н.И. Формирование информационной культуры личности в библиотеках и образовательных учреждениях : учеб.-метод. пособие / Н.И. Гендина,
Н.И. Колкова, И.Л. Скипор, Г.А. Стародубова. 2-е изд., перераб. Москва : Школьная библиотека, 2003. 295 с.

6. Малонтова М.С. Развитие информационной компетентности библиотечного специалиста в современном обществе // Вестник Марийского государственного университета. 2010. № 5. С. 273-276.

7. Ракитская Л.М. Лекция-тренинг - эффективная форма обучения пользователей поиску документов в справочно-правовых системах : (Опыт Центра правовой информации РГБ) // Научные и технические библиотеки. 2012. № 12. С. 5-12.

8. Елепов Б.С., Крючкова Е.М. Компетентность и компетенции библиотечного специалиста: как и зачем их оценивать // Библиотековедение. 2009. № 3. C. $117-124$.

\title{
Methodical Work on Formation of Information Competence of Librarians Working with Legal Information Systems
}

\author{
Liliya M. Rakitskaya,
}

The Russian State Library, 3/5 Vozdvizhenka Str., Moscow, 119019, Russia

E-mail: 1-rakitskaya@yandex.ru

\begin{abstract}
The article highlights the issues of free access of users to information resources in libraries on the example of specifics of librarians work with the legal information systems (LIS). In this regard, there are analyzed the issues of development of professional competencies in the field of libraries. It is presented the training used at the Russian State Library as a method of formation of information competence and shown its effectiveness for the users of legal information systems ("Consultant Plus", "Garant", "Techexpert", "CIS Legislation"), as well as official web portals (LIS "Legislation of Russia", Research Center of Legal Information "Etalon", etc.). There are disclosed component parts of the training: flow chart for design of lessons, examples of training tasks. The article represents the results of survey conducted among the users to get their estimate of the contents and form of training lectures, to identify their level of knowledge and skills in operating with the legal information systems. There are given guidelines for librarians on the basis of competency-based approach in the use of LIS. The results of the research can be used by libraries in the practice of methodical work for the formation of professional competencies of library staff, working with the legal information systems, and other electronic resources.
\end{abstract}

Key words: Libraries, Library Services, Users, Information Resources, Legal Information Systems, Competency-Based Approach, Information Competence, Training, Methodical Work.

Citation: Rakitskaya L.M. Methodical Work on Formation of Information Competence of Librarians Working with Legal Information Systems, Bibliotekovedenie [Library and Information Science], 2016, vol. 65 , no. 6 , pp. $701-708$.

\section{References}

1. Shelmenkov V.N. Pravovoe obespechenie funktsionirovaniya informatsionno-spravochnykh sistem v Rossiiskoi Federatsii [Legal Support of Functioning of Directory Systems in the Russian Federation], Monitoring pravoprimeneniya [Monitoring of Law Enforcement], 2012, no. 3, pp. 52-56.

2. Belitskaya I.Ya., Koryakina Yu.S., Kuznetsov D.L. Priem na rabotu. Zaklyuchenie trudovogo dogovora: ucheb.-prakt. posobie [Employment. Conclusion of the Employment Contract: the Training Manual]. Moscow, Kontrakt Publ., Volters Kluver Publ., 2011, $288 \mathrm{p}$.

3. Parshukova G.B. Informatsionnaya kompetentnost' lichnosti. Diagnostika i formirovanie: monografiya [Information Competence of Personality. The Diagnostics and Formation: the Monograph]. Novosibirsk, 
Novosibirskii Gosudarstvennyi Tekhnicheskii Universitet Publ., 2006, 253 p.

4. Gendina N.I. Informatsionnaya gramotnost' ili informatsionnaya kul'tura: al'ternativa ili edinstvo (rezul'taty rossiiskikh issledovanii) [Information Literacy or Information Culture: the Alternative or Unity (the Results of Russian Studies)], Shkol'naya biblioteka [School Library], 2005, no. 3, pp. 18-24.

5. Gendina N.I., Kolkova N.I., Skipor I.L., Starodubova G.A. Formirovanie informatsionnoi kul'tury lichnosti $v$ bibliotekakh i obrazovatel'nykh uchrezhdeniyakh: ucheb.-metod.posobie [Formation of the Information Culture in Libraries and Educational Institutions: the Guidance Manual]. Moscow, Shkol'naya Biblioteka Publ., 2003, 295 p.

6. Mamontova M.S. Razvitie informatsionnoi kompetentnosti bibliotechnogo spetsialista v sovremennom obshchestve [Development of the Information Compe- tence of Library Specialist in the Modern Society], Vestnik Mariiskogo gosudarstvennogo universiteta [Vestnik of Mari State University], 2010, no. 5, pp. 273-276.

7. Rakitskaya L.M. Lektsiya-trening - effektivnaya forma obucheniya pol'zovatelei poisku dokumentov v spravochno-pravovykh sistemakh: (Opyt Tsentra pravovoi informatsii RGB) [Lection-Training - an Efficient Form of Training Users in Searching the Documents in Legal Information Systems (The Experience of the RSL Legal Information Center)], Nauchnye i tekhnicheskie biblioteki [Scientific and Technical Libraries], 2012, no. 12, pp. 5-12.

8. Elepov B.S., Kryuchkova E.M. Kompetentnost' i kompetentsii bibliotechnogo spetsialista: kak i zachem ikh otsenivat' [Competence and Expertise of a Library Specialist: How and Why to Evaluate Them], Bibliotekovedenie [Library and Information Science], 2009 , no. 3 , pp. $117-124$.

\section{Aнонс}

Федеральное государственное бюджетное учреждение «Российская государственная библиотека»

\section{Учебный центр послевузовского и дополнительного профессионального образования специалистов}

Лицензия на осуществление образовательной деятельности № 0010 от 29 мая 2012 2. выдана Федеральной службой по надзору в срере образования и науки

объявляет набор на $2017 / 2018$ учебный год сотрудников библиотек РФ и стран СНГ, а также частных лиц, имеющих высшее или среднее профессиональное образование по образовательной программе профессиональной переподготовки «Высшие библиотечные курсы - дистант» (очная - заочная форма, с использованием дистанционных образовательных технологий): 650 учебных часов.

Сроки реализации образовательной программы:

- февраль - май 2017 г., итоговая аттестация - июнь 2017 г.

- сентябрь - декабрь 2017 г., итоговая аттестация - январь 2018 г.

По окончании обучения выдается документ о квалификации - «Диплом о профессиональной переподготовке» установленного образца, дающий право на ведение профессиональной деятельности в библиотечно-информационной сфере.

Оплата за обучение осуществляется в соответствии с Прейскурантом Российской государственной библиотеки.

Адрес: Москва, ул. Воздвиженка, д. 1, 4 этаж.

Проезд: м. «Библиотека им. Ленина», «Арбатская», «Боровицкая».

Телефоны для справок: + 7 (495) 695-98-89, 695-93-12.

Прием документов: понедельник - пятнииа с 10:00 до 18:00.

E-mail:vbk@rsl.ru 